\title{
Investigation of a cyclic laterally loaded model pile group
}

\author{
Robb Eric S. Moss, Joseph A. Caliendo \& Loren R. Anderson \\ Department of Civil and Environmental Engineering, Utah State University, Logan, UT 84322-4110, USA
}

\begin{abstract}
In certain regions of the world, designing deep foundations to withstand seismic loading is a reality. Seismic loading of structures and foundations reaches its most critical state as a cyclic lateral force. The response of soils and foundations to repetitive lateral forces is highly complex, relegating most design methods to be based upon overly conservative rules-of-thumb. The primary objective of this research was to analyze the mechanics of seismic loading on pile groups in clay soils. To achieve this a model testing facility was constructed to house a fully instrumented $1 \times 5$ model pile group that was subjected to cyclic lateral loading. An empirically based method for pile group design is suggested based upon the results generated from model pile group testing.
\end{abstract}

Key words: pile tests, lateral loads, model tests, pile groups.

\section{EQUIPMENT AND INSTRUMENTATION}

The objective of this research was to define more clearly the response of pile groups in clay soils and ultimately mitigate seismic hazard by increasing the confidence in deep foundation design when cyclic loads are a concern. The cost of testing full scale deep foundations is prohibitively expensive for repeated tests, therefore, a model testing facility was developed at Utah State University to run multiple tests in a cost and time conscious manner. This project was funded by the Utah Department of Transportation and the Mountain Plains Consortium.

The model test facility is a large steel tank, approximately 3 by $1 \mathrm{~m}$ in plan view and $1.2 \mathrm{~m}$ high. This tank was lined with a geomembrane and geofabric. A silty clay soil (CL) was placed into the tank in slurry form and then consolidated using hydraulic rams pushing on overlying steel plates. Excess pore pressure was dissipated through the geofabric and out exit drains. The clay was consolidated to an average undrained shear strength of $40 \mathrm{kPa}$. The clay was maintained in a saturated state throughout the testing.

The model pile group is composed of five piles arranged in a linear fashion, pinned at the top to a pile cap (see Fig. 1). A linear pile group allowed for focus on group and shadowing effects. A pinned connection was chosen because it could be modeled precisely. A pile spacing of $3 d$ was chosen for this test $(\mathrm{d}=$ outside diameter). The prototype pile $(\mathrm{OD}=324 \mathrm{~mm}$ and wall thickness $=9.53 \mathrm{~mm}$ ) is a typical closed-end steel pipe pile commonly used by the Utah DOT. Similitude considerations were adhered to when designing the model piles. The piles were fabricated from 6061 aluminum pipe with an OD of $33.4 \mathrm{~mm}$ and a wall thickness of $3.38 \mathrm{~mm}$. The piles were $1.52 \mathrm{~m}$ long of which $85 \%$ was embedded into the soft clay.

In order to measure the pile-soil-pile response to cyclic lateral loading, a sophisticated measuring system was devised. Each pile was instrumented with 14 pairs of foil strain gages evenly spaced throughout the length of the piles. Each strain gage pair was diametrically mounted on the inside wall of the aluminum tube and epoxied in place using a unique installation tool designed and built by the USU Civil Engineering Shop. Strain gage load cells were mounted on the pile cap between each pile to measure load distribution. Master load cells were located at each end of the pile cap to measure the total group load. Two LVDT's (Linear Variable Differential Transformers) were utilized to measure the pile top displacement and slope. With the addition of a sixth pile to compensate for temperature changes and electrical noise, the measuring system was comprised of 182 channels of output. 


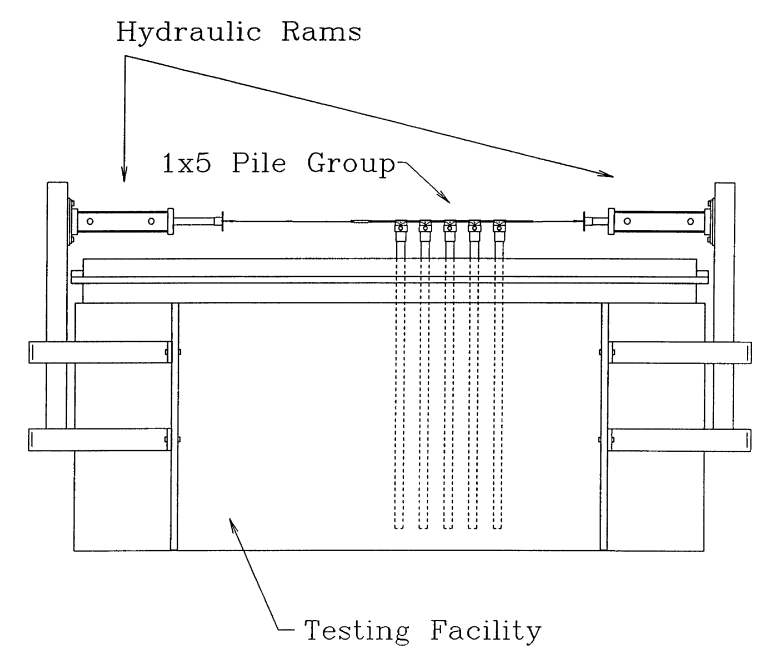

Fig. 1. Model pile testing facility.

A highly specialized data acquisition system was designed and built in-house to acquire 182 channels of information in an expedient manner. The four main components of the system were a PC, A/D board, power supply and acquisition hardware. There is a full Wheatstone bridge for each strain gage: one strain gage in a pile accompanied by three resistors located on their respective circuit boards. Fourteen circuit boards were needed to acquire all 182 channels of information. The acquisition system is controlled by LabVIEW software, which also controls the loading system in a closed loop format.

Cyclic lateral loading of the pile group was accomplished via hydraulic rams. The hydraulic rams were mounted horizontally in plane with the pile cap. Loading force was provided by a hydro-pneumatic tank and regulator. The actuation of the loading force was controlled by a solenoid switch which was in turn controlled by LABVIEW. The program was written using LABVIEW software which gave real time analysis of group load, pile top deflection and slope, bending stresses in each pile, and the maximum stress in any one pile during the test.

\section{TESTING}

A load scheme was designed after generating predictions using FLORIDA-PIER and Com624P software, and trial and error testing in the lab. The pile group was laterally loaded from zero to $2000 \mathrm{~N}$ and back to zero in approximately $1 \mathrm{~min}$ while the acquisition system recorded data at the rate of four samples a second. That is 182 channels recorded in $0.25 \mathrm{~s}$, acquired continuously throughout the loading. The group was then loaded in the same manner but in the opposite direction, thus completing one cycle. This was carried out for 50 cycles of loading. The complete test yielded 52 megabytes of data, read continuously for every cycle, encompassing loads from 0 to $2000 \mathrm{~N}$ for each cycle.
Load, as opposed to strain or hertz, was chosen as the control for testing. During an earthquake, a structure and its foundation will experience forces at some peak level. The force level applied to the pile group was $\approx 65 \%$ of the yield stress of the aluminum model piles. The peak load value was achieved every cycle, this premise based upon previous research on clays experiencing cyclic loading ${ }^{1}$.

The loading scheme was designed to look at the mechanics of cyclic lateral loading of pile groups, not dynamic responses involving inertial or kinematic effects. This phase of the research targeted soil degradation due to load and cycle, and a comparison of these results with predicted results from design software. Undrained conditions were maintained throughout the test to simulate the soil conditions during a seismic event. During ground shaking, a clay soil has no time to dissipate excess pore pressure generated by the seismic motion. Although the cycle rate used in these model tests were of low frequency, it is assumed that maintaining undrained conditions significantly minimizes frequency as a variable when considering deflection, maximum bending moment, moment distribution, load distribution, pile shadowing, group effects, and other mechanical interactions between the pile group and the surrounding soil.

Upon completion of the cyclic load test a final calibration test was necessary to determine exact correlation between measured voltages and bending stresses. This was done using the cyclic load testing set up with the program slightly modified for calibration. A known load was applied to the piles at a known location and then the measured output was compared to the theoretical bending stresses. A linear regression was done on the comparison. The result was a calibration factor for each gage which fine tuned the raw output.

For a full description of equipment, instrumentation, testing, and a complete catalogue of the results see Refs ${ }^{2-5}$.

\section{APPLICATION OF MOMENT AND DEFLECTION RESULTS}

Moment distribution and load versus deflection were two groups of results that were generated. Fig. 2 and Fig. 3 are plots of group moment distributions for cycles 1 and 50 at a lateral load of $2000 \mathrm{~N}$. The curves are shown for all five piles, loaded in one direction and then the other. The outer curves are the lead piles and all subsequent curves are from their respective pile row positions; the lead piles taking the majority of the load in all cases and exhibiting the highest bending moment. These two plots show a progression of maximum bending moment traveling down the length of the piles as the number of cycles increases. This is due to the gapping that occurs at the clay surface. Fig. 4 is a moment distribution plot of a single pile showing the slight increase in maximum bending moment as the number of cycles increase. Fig. 5 is a plot of load versus pile top deflection. 


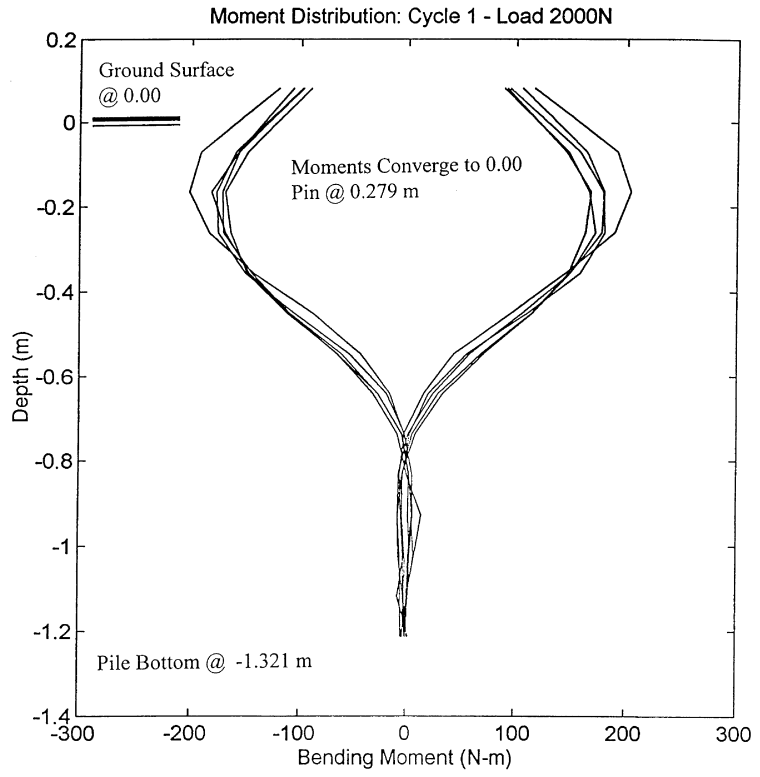

Fig. 2. Moment distribution for each pile, maximum load, cycle 1 .

The gapping can be seen in this plot as the initial offset of each curve after cycle 1 .

To utilize these results in a full scale design scenario the information was normalized and presented in a dimensionless form; see Fig. 6 and Fig. 7. The dimensionless variables used for plotting the deflection and bending moment results include all pertinent variables $(\mathrm{EI}=$ pile stiffness and $\mathrm{D}=$ pile diameter). In order to use these normalized curves, one would enter into them with a design load $(\mathrm{P})$ induced at the pile cap, and specific pile properties (EI and D). The expected pile top deflection and maximum bending moment in the lead pile can then be predicted. At this time these results are only valid for similar clay soil profiles

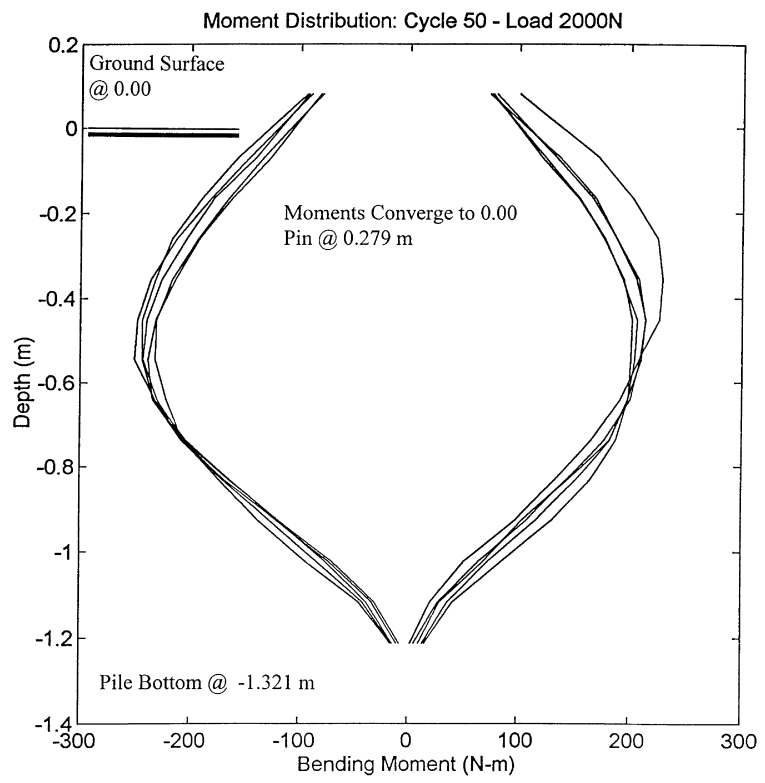

Fig. 3. Moment distribution for each pile, maximum load, cycle 50 .

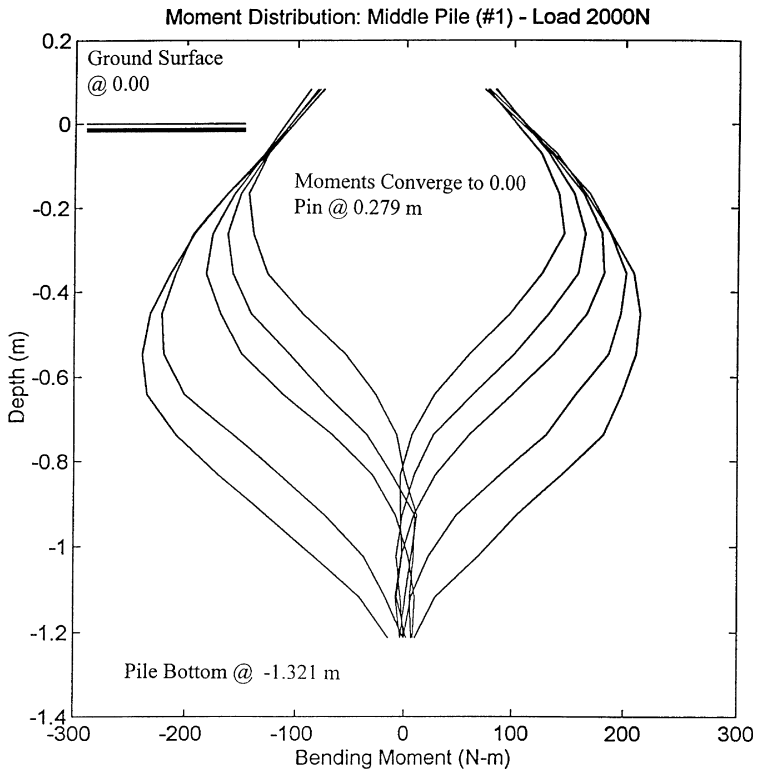

Fig. 4. Moment distribution, middle pile, maximum load, cycles $1-50$.

and stickup length (i.e. $\mathrm{CL}$ with an average undrained shear strength of $40 \mathrm{kPa}$ ). Also these predictions are likely to be conservative for any loads corresponding to model loads less than the maximum test load. Further testing is underway to cover a wider spectrum of clay strengths from soft to very stiff and for various locations of applied load. Additionally, the loading procedure will be modified to account for the consequences of the pile being subjected to a load that is higher than the previous cycled load. This causes the pile to initially move through a remolded soil, particulary near the ground surface at the soil gap.

The results of the $1 \times 5$ model pile group can be extra-

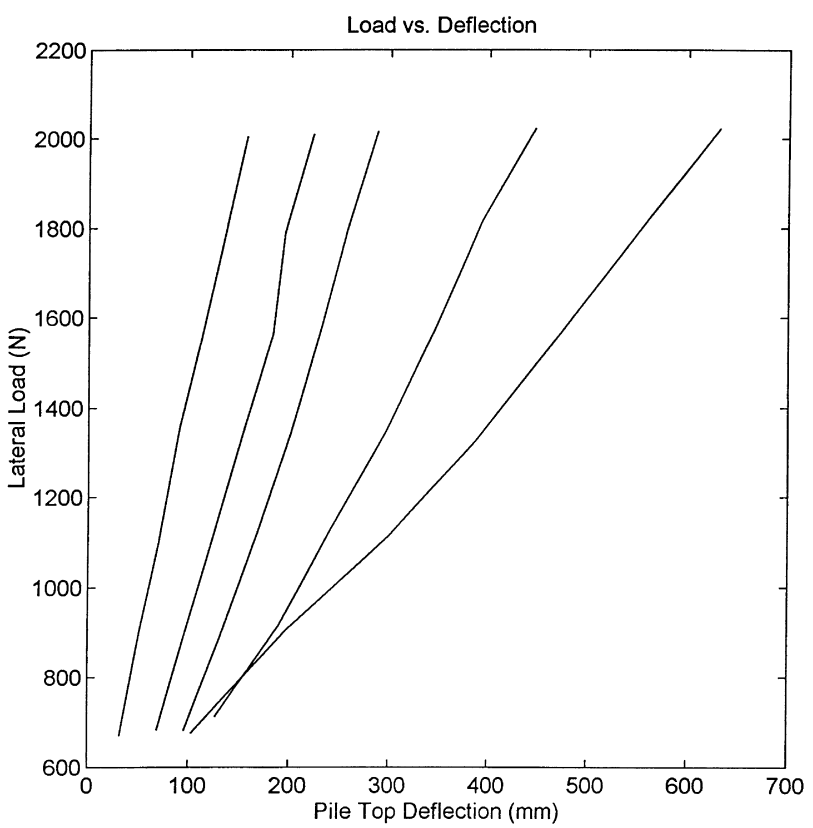

Fig. 5. Pile group, top deflection versus applied load, cycles 1-50. 


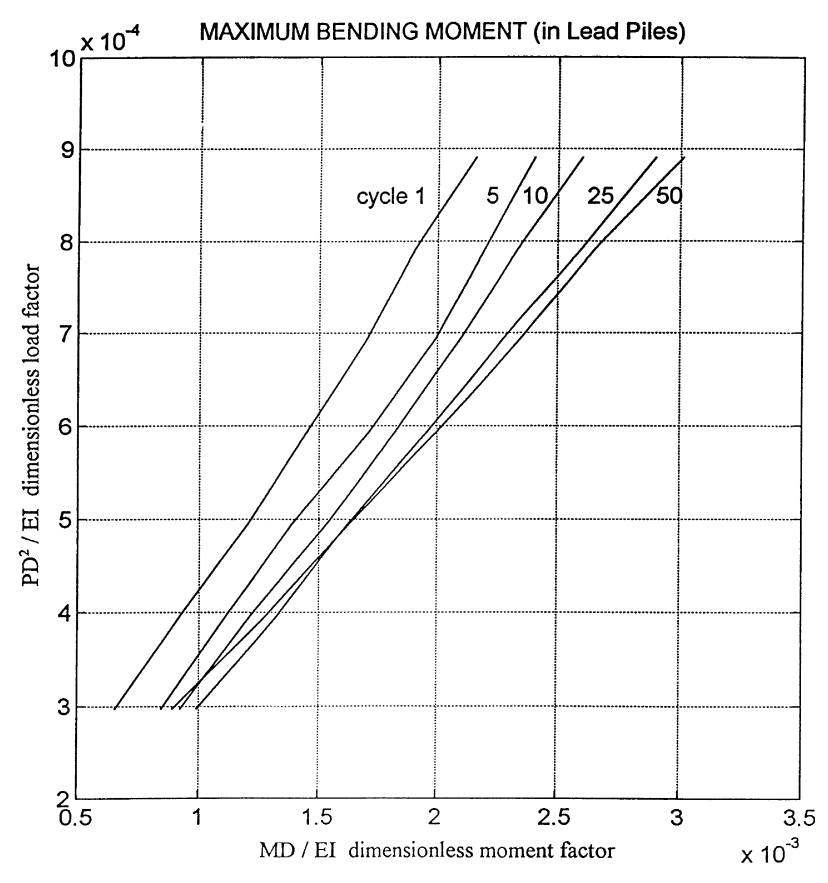

Fig. 6. Dimensionless factors for maximum bending moment.

polated to a $n \times 5$ pile group under the assumption that group and shadowing effects are predominantly a function of pile row position and not column position as suggested by Brown and Reese ${ }^{6}$. Therefore, this method allows a designer to predict bending moment and deflection of a $5 \times 5$ pile group in a CL soil with similar undrained shear strength. Further testing is in order to encompass different pile group geometries.

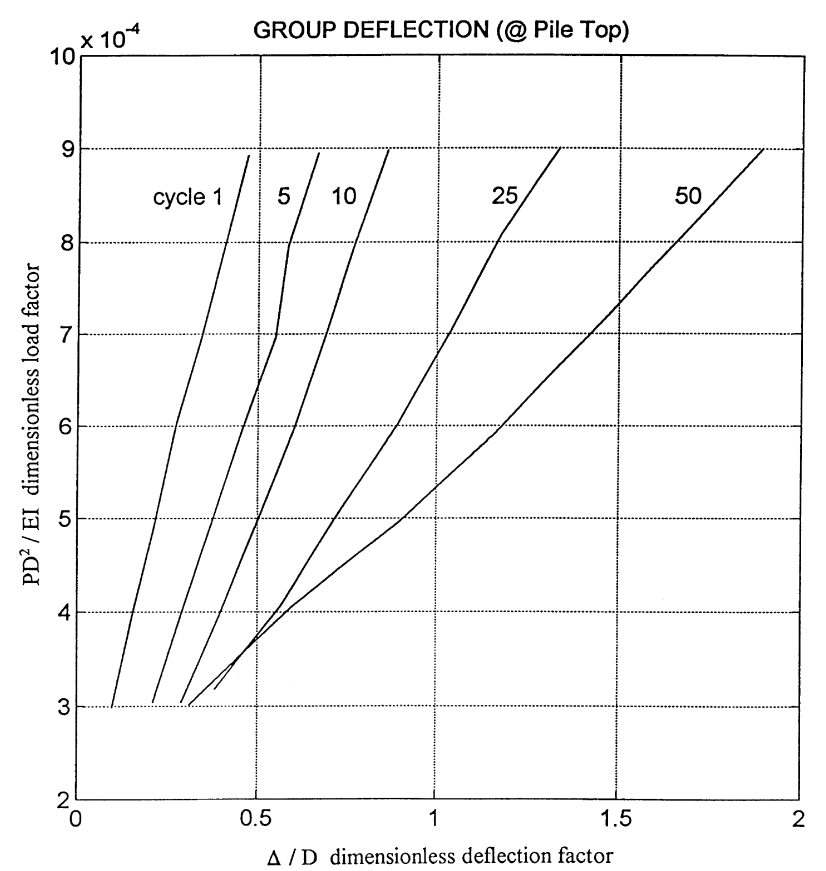

Fig. 7. Dimensionless factors for pile top deflection.

\section{USE OF DIMENSIONLESS RESULTS}

Currently, designing deep foundations for seismic loading involves using software packages that in the most part rely on $p-y$ curves for defining the non-linear lateral response of soils. Some programs use a finite element approach which is quite costly and time consuming for large foundations. $p-y$ curves work but are a highly generalized solution to a complex phenomena. The use of $p-y$ curves for clays often fails to account for increased degradation of the soil with an increase of cycles. The default $p-y$ curves provided by software packages have an option of either static or cyclic but typically do not account for the permanent deformation that occurs with each increasing cycle.

The normalized curves presented in this paper are the first step towards an empirically based design method that eliminates the use of $p-y$ curves. Upon further testing for various soil strengths, soil profiles, and pile group geometries, a software package can be written for use in design. This design method shows promise because of its simplicity and ease of use.

\section{ADDITIONAL OBSERVATIONS}

The moment and deflection results were reduced to provide further insight into other group trends. Fig. 8 is a plot showing the relationship of the maximum bending moment to the number of cycles. The abscissa is the ratio of the maximum bending moment in the lead pile at cycles 1 to $n$. It can be seen that the maximum bending moment increases nonlinearly with cycles and starts to taper off somewhere

Maximum Bending Moment Ratio for Cycles 1-50

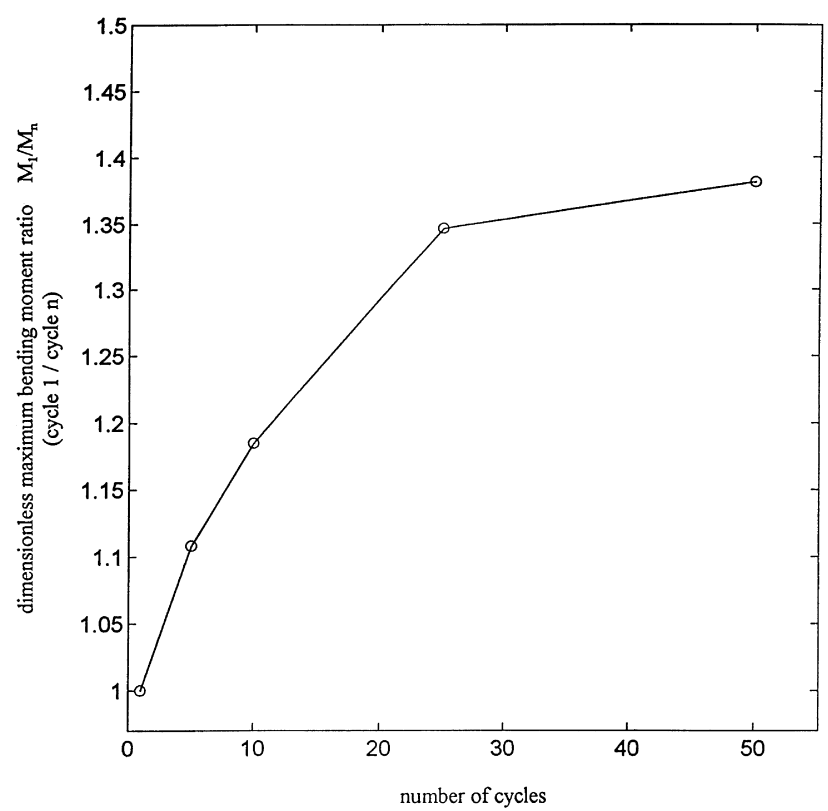

Fig. 8. Maximum bending moment ratio, cycles 1-50. 


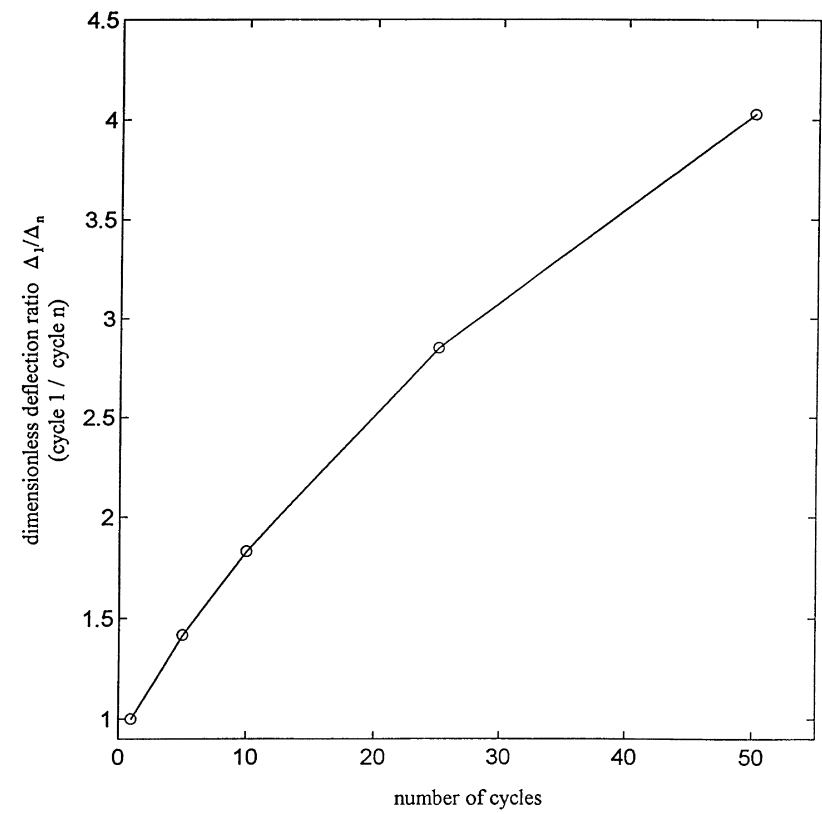

Fig. 9. Pile top deflection ratio, cycles 1-50.

after cycle 25. This trend was also seen in plots of depth to the point of maximum bending moment with cycles. Fig. 9 shows the relationship between pile top deflection and the number of cycles. Again the abscissa is a ratio, the ratio of pile top deflection at cycles 1 to $n$. The resulting curve is much more linear.

\section{FINAL COMMENTS}

The objective of this ongoing research is to improve seismic design of deep foundations in clay by creating a model testing facility in which to study pile group response to cyclic lateral loads. The first phases of the testing have been completed and the results are promising both in terms of increasing the body of knowledge about pile groups and producing tools that can be used in practice.

\section{REFERENCES}

1. Seed, H.B. and Chan, C.K. Clay strength under earthquake loading conditions. Journal of Soil Mechanics and Foundations Division, American Society of Civil Engineers, 1966, 92(SM2), 53-78.

2. Caliendo, J.A. \& Anderson, L.R. Lateral load testing of model piles, phase 1. Report no. 96-60 to the Mountain Plains Consortium, Utah Transportation Center, 1996.

3. Caliendo, J.A. et al. Instrumentation for laterally loaded piles. Small-magnitude measurements in geotechnical engineering, transportation research record no. 1548, 1996.

4. Rawlings, M.A. Cyclic lateral loading of model pile groups in clay: phase 2A. Masters thesis, Department of Civil and Environmental Engineering, Geotechnical Division, Utah State University, Logan, UT, 1997.

5. Moss, R.E.S. Cyclic lateral loading of model pile groups in clay: phase 2B. Masters thesis, Department Civil and Environmental Engineering, Geotechnical Division, Utah State University, Logan, UT, 1997.

6. Brown, D.A. \& Reese, L.C. Behavior of a large-scale pile group subjected to cyclic lateral loading. Geotechnical engineering report GR85-12, Geotechnical Engineering Center, Bureau of Engineering Research, Austin, TX, 1985. 